\title{
Anaphylactic shock during cement implantation of a total hip arthroplasty in a patient with underlying mastocytosis: case report of a rare intraoperative complication
}

\author{
Anita ten Hagen ${ }^{1}$, Pieter Doldersum ${ }^{1}$ and Tom van Raaij ${ }^{2^{*}}$
}

\begin{abstract}
Background: Cemented total hip arthroplasty (THA) is a safe and common procedure. In rare cases life threatening bone cement implantation syndrome (BCIS) may occur, which is commonly caused by pulmonary embolism (PE).

Case presentation: We describe the rare case of a 70-year old patient who underwent an elective total hip replacement. Before surgery he was diagnosed with underlying systemic indolent mastocytosis, a rare pathological disorder that may result in anaphylaxis after massive systemic mast cell activation. Triggers may be IgE-mediated, direct mast cell activation, or unclear. Some patients may be at risk for severe non lgE-mediated reactions, such as those experienced with nonsteroidal anti-inflammatory drugs, or with perioperative muscle relaxants. During cementing of the acetabular component, our patient developed acute hypotension (blood pressure dropped from $90 / 50$ to $60 / 40 \mathrm{mmHg}$, and saturation dropped from 95 to $80 \%$ ). The differential diagnosis of acute PE was excluded (no signs of breathing abnormalities during physical examination, normal arterial blood sample, and no electrocardiography or cardiac ultrasound abnormalities). The patient was diagnosed with acute anaphylactic shock, which was successfully managed by $100 \%$ oxygen administration, rapid fluid induction, and vasoconstrictive drug therapy. He recovered hemodynamically within $15 \mathrm{~min}$, did not lose consciousness, and did not develop angioedema or an urticarial rash. Forty-five minutes after onset of the symptoms, the surgical procedure was completed after inserting a press fitted uncemented femoral stem component. The patient was transported to the Intensive Care Unit (ICU) for optimal monitoring. Our patient had an uneventful recovery. Within six hours after surgery he started to ambulate following our standard fast-track rehabilitation regime. Post-operative day one he was discharged to the specialized Orthopedic Department, and after five hospital days discharged to his home. Twelve months after THA surgery our patient was satisfied with an optimal functional status of his hip joint replacement.

Conclusion: The differential diagnosis of anaphylactic shock must be taken into consideration in patients with acute hypotension during cementing of total hip arthroplasty components. Patients with underlying mastocytosis are at particular risk of this potential life-threatening intra-operative complication. This rare entity should be taken into consideration during the pre-operative risk stratification and shared decision-making process for elective cemented joint replacement.
\end{abstract}

Keywords: Mastocytosis, Bone cement, Implantation syndrome, Anaphylaxis, Hip surgery, Case report

\footnotetext{
* Correspondence: t.m.vanraaij@mzh.nl

${ }^{2}$ Department of Orthopaedic Surgery, Martini Hospital Groningen, van

Swietenplein 1, 9728 NT Groningen, The Netherlands

Full list of author information is available at the end of the article
} 


\section{Background}

BCIS is characterized by a number of clinical features that may include hypoxia, hypotension, cardiac arrhythmias, increased pulmonary vascular resistance, and cardiac arrest. BCIS is most commonly associated with hip arthroplasty, and usually occurs at one of the five stages in the surgical procedure; femoral reaming, acetabular or femoral cement implantation, insertion of the prosthesis or joint reduction [1]. High incidence with severe reactions has been reported in cemented hemiarthroplasty after a proximal femur fracture. In elective THA surgery the incidence has been much lower, but still the rate of intraoperative mortality is about $0.1 \%$ [2]. Diverse mechanisms have been postulated as causing BCIS [1]. An anaphylactoid mechanism as a major factor contributing to the development of BCIS remains disputed. Earlier, Tryba et al. showed increased levels of plasma histamine in elderly patients with hip fractures after the implantation of acrylic bone cement into the femur [3]. Mitsuhata et al. concluded that methylmethacrylate bone cement does not release histamine during total hip replacement surgery [4]. A randomized trial in 50 patients receiving cemented hip arthroplasty could not demonstrate a prophylactic potential for histaminereceptor blocking agents in BCIS [5]. Since then, many studies have suggested that pulmonary embolization is the main cause in BCIS [1]. Mastocytosis is a rare pathological disorder that may result in anaphylaxis after massive systemic mast cell activation. Triggers may be IgE-mediated, direct mast cell activation, or unclear. IgE-mediated anaphylaxis to drugs and foods are not well studied [6]. We describe a patient diagnosed with systemic indolent mastocytosis who most likely developed an anaphylactoid BCIS response after acetabular component cementation in elective total hip surgery.

\section{Case presentation}

A-70-year-old man with symptomatic osteoarthritis of the right hip, weighing $79 \mathrm{~kg}$, tall $177 \mathrm{~cm}$ was presenting for a primary THA. He was recently diagnosed with systemic indolent mastocytosis with multiple sclerotic and osteolytic laesions. History showed no allergic reactions in the past. In 1998 cannulated hip screws were used to treat a left proximal transcervical femur fracture successfully. Multiple insufficiency vertebra fractures were treated non-operative in 2015. A multimodal oral analgesic regime consisting of paracetamol $1 \mathrm{~g}$, naproxen $500 \mathrm{mg}$ and gabapentin $600 \mathrm{mg}$ was administered $1-2 \mathrm{~h}$ pre-operatively. On the pre-anesthetic care unit the blood pressure was $150 / 95 \mathrm{mmHg}$ with a saturation of $95 \%$ and 11,85 mg Dexamethasone and Cefazoline $2000 \mathrm{mg}$ soluted in $20 \mathrm{ml}$ Sodiumchloride $(\mathrm{NaCl}) 0.9 \%$ was administered intravenously. In the operating room spinal anesthesia with $7.5 \mathrm{mg}$ bupivacaine $0,5 \%$ plain via the L2/3 vertebral interspace with a standardized intraoperative regime for fluid administration, consisting of $0,9 \%$ saline $(500 \mathrm{ml})$ was given. After spinal anesthesia the patient received sedation with propofol TCI 0,8 ug/ $\mathrm{ml}(0,1-2.0 \mathrm{ug} / \mathrm{ml})$. To reduce blood loss, tranexamic acid $1000 \mathrm{mg}$ was given at the beginning of surgery. To reduce nausea and vomiting ondansteron $4 \mathrm{mg}$ IV is added in this multimodal regimen. To reduce chronic pain, ketamine $15 \mathrm{mg}$ IV is titrated after starting the sedation. The blood pressure was $120 / 70 \mathrm{mmHg}$ after spinal anesthesia and starting the sedation. Three liter of Oxygen was added during sedation. Thirty minutes after induction the orthopedic surgeon inserted a cemented acetabular component. Blood pressure dropped from 90/ 50 to $60 / 40 \mathrm{mmHg}$. Saturation dropped from 95 to $80 \%$. Oxygen $100 \%$ with a Ventimask was administered and rapid infusion of $\mathrm{NaCl} 0.9 \% 1000 \mathrm{ml}$ as well as Phenylephrine $4 \times 100 \mathrm{ug}$, phenypephrine $2 \times 200 \mathrm{ug}$ and $10 \mathrm{mg}$ ephedrine was given intravenously. Phenylephrine infusion was started and replaced by Noradrenaline $5 \mathrm{mg} / 50 \mathrm{ml} \mathrm{NaCl} 0.9 \% 2.0-9.0 \mathrm{ml} / \mathrm{h}$. The breath sounds remained normal, and no angioedema, urticaria or rash occurred. All the time, the patient was conscious and able to respond questions. With rapid infusion and finally Noradrenaline he recovered hemodynamically within $15 \mathrm{~min}$, blood pressure 100/50 mmHg with $95 \%$ saturation. Forty-five minutes after onset of the symptoms, the surgical procedure was completed after inserting a press fitted uncemented femoral stem component. The patient was transported to the Intensive Care Unit (ICU) for optimal postoperative treatment and monitoring. Biochemistry showed stable hemoglobin levels $(8.3 \mathrm{mmol} / \mathrm{l}$ on ICU arrival and $8.4 \mathrm{mmol} / \mathrm{l}$ after $4 \mathrm{~h}$ ), elevated white blood cell count $\left(19.3 \times 10^{9} / 1\right)$, normal levels of electrolytes, liver enzymes, creatine kinase and troponin, and an arterial blood sample of pH 7.36 pCO2 $6.1 \mathrm{kPa}$; pO2 14.4 kPa; HCO3 $26 \mathrm{mmol} / \mathrm{l}$; Base excess $0.4 \mathrm{mmol} / \mathrm{l}$; Fys. O2 sat $98.7 \%$; FiO2 $30 \%$; lactic acid $1.0 \mathrm{mmol} / \mathrm{l}$. Electrocardiography (on ICU arrival and after $24 \mathrm{~h}$ ) remained normal, and echocardiography showed no left or right ventricular disfunctioning or elevation of the right atrial pressure. Within six hours after surgery the patient started to ambulate following our standard fast-track rehabilitation regime. Post-operative day one he was discharged according strict functional criteria to the specialized Orthopedic Department. After 5 hospital days the patient was discharged to his home.

\section{Discussion}

BCIS has been observed in prosthetic hip surgery for many years, and is still not fully understood. A severity classification has been proposed; grade 1: moderate hypoxia $(\mathrm{SpO} 2,94 \%)$ or hypotension [fall in systolic blood pressure (SBP) .20\%], grade 2: severe hypoxia (SpO2 
,88 \%) or hypotension (fall in SBP .40 \%) or unexpected loss of consciousness, and grade 3: cardiovascular collapse requiring cardiopulmonary resuscitation [1]. In our case a grade 2 BCIS occurred after cementing the acetabular component; systemic blood pressure drop more than $30 \%$ and severe hypoxia (saturation $80 \%$ ). The patient recovered in $15 \mathrm{~min}$ after rapid fluid induction, $100 \%$ oxygen administration, and vasoconstrictive drug therapy. He did not lose consciousness, did not develop angioedema or an urticarial rash, and remained hemodynamic stable with blood loss not more than expected after elective hip surgery. All our eligible patients receive cemented acetabular components during total hip surgery. Nationwide registry shows better performance of cemented cups over uncemented cups [7]. Also less damage to the acetabular host bone with a cemented component during future revision surgery is to be expected [8]. Acetabular pressure rises after cup placement, especially during cementation, and an average of $375 \mathrm{mmHg}$ has been reported [9]. As a consequence extrusion of bone marrow content with diffuse microembolism of the lungs may occur. In our case pulmonary fat embolism was excluded; there were no signs of breathing abnormalities during physical examination, only a short period of hypoxia occurred, and no electrocardiography or cardiac ultrasound abnormalities were encountered. Normovolemic hypotension without angioedema or rash may also be caused by an anaphylactoid mechanism observed in mastocytosis [6]. Recently our patient was diagnosed with systemic indolent mastocytosis through an iliac crest biopsy. Anaphylaxis in mastocytosis can be either IgE-mediated or non IgE-mediated, such as those experienced with nonsteroidal antiinflammatory drugs or muscle relaxants. In our hospital all primary THA patients undergo a standardized anesthesia, analgesia and perioperative program to enhance recovery. Low dose bupivacaine and a multimodal opioid-sparing regimen facilitate early mobilization and allow rehabilitation to be initiated a few hours postoperatively. Our patient received intravenous nonsteroidal anti-inflammatory drugs at least one hour preoperatively, and no muscle relaxants were given. The acute response after cement application suggests a reaction on polymethylmethacrylate (PMMA) bone cement. Earlier, PMMA mediated histamine release with increased plasma histamine concentrations after bone cement implantation in the femoral shaft has been described [4]. More recent hypersensitivity to PMAA following joint replacement has also been reported [10, 11]. Krüger et al. described a patient with mastocytosis who underwent kyphoplasty for multiple osteoporotic vertebral fractures using radiopaque calcium phosphate bone cement under antihistamine and prednisolone coverage [12]. Arterial hypotension was encountered that transiently required vasopressor support. The critical threshold of intramedullary pressure that causes fat embolism is unclear, but pressure peaks as great as $300 \mathrm{mmHg}$ were found to produce significant bone marrow release [13]. Intravertebral pressure during kyphoplasty, however, is substantially lower, and remains well below $300 \mathrm{mmHg}$ [14]. A pressure-induced mast cell degranulation mechanism seems more suitable. Although rare an allergic reaction to calcium phosphate cement has been noted in skull reconstruction [15]. Even severe hypoxia with ventricular failure as a sign of possible aggregate anaphylaxis has been seen after formation of intravenous calcium phosphate precipitant [16]. Therefore, it seems more likely that Krügers' observation and our case highlight the capacity of bone cement to trigger a disproportionate display of mast cell activity in mastocytosis patients with a BCIS response as a result. The use of corticosteroids has been advised to prevent anaphylaxis in patient with mastocytosis. In both patients corticosteroids were administered before intervention, which did not prevent BCIS unfortunately.

\section{Conclusion}

Our case suggests a disproportionate response to PMMA bone cement, which lead to anaphylactic shock. Patients with underlying mastocytosis are at particular risk of this potential life-threatening intra-operative complication. This rare entity should be taken into consideration during the preoperative risk stratification and shared decision-making process for elective cemented joint replacement.

\section{Acknowledgements}

N/A.

\section{Funding}

No funding was obtained for the design of the study and collection, analysis, and interpretation of data and in writing the manuscript.

\section{Availability of data and materials}

Data sharing not applicable to this article as no datasets were generated or analysed during the current study.

Authors' contributions

AH, PD and TR made substantial contributions to conception and design, acquisition of data, and analysis and interpretation of data; All authors have been involved in drafting the manuscript and revising it critically for important intellectual content; All authors have given final approval of the version to be published. Each author has participated sufficiently in the work to take public responsibility for appropriate portions of the content; and all authors agreed to be accountable for all aspects of the work in ensuring that questions related to the accuracy or integrity of any part of the work are appropriately investigated and resolved.

Competing interests

The authors declare that they have no competing interests.

Consent for publication

Written informed consent for publication of their clinical details was obtained from the patient. 


\section{Ethics approval and consent to participate}

N/A.

\section{Author details}

'Department of Anesthesiology, Martini Hospital Groningen, Van Swietenplein 1, 9728 NT Groningen, The Netherlands. ${ }^{2}$ Department of Orthopaedic Surgery, Martini Hospital Groningen, van Swietenplein 1, 9728 NT Groningen, The Netherlands.

Received: 5 October 2016 Accepted: 27 October 2016

\section{Published online: 05 November 2016}

\section{References}

1. Donaldson AJ, Thomson HE, Harper NJ, Kenny NW. Bone cement implantation syndrome. Br J Anaesth. 2009;102(1):12-22. doi:10.1093/bja/ aen328. Review.

2. Griffiths R, Parker M. Bone cement implantation syndrome and proximal femoral fracture. Br J Anaesth. 2015;114(1):6-7. doi:10.1093/bja/aeu264. Epub 2014 Aug 21.

3. Tryba M, Linde I, Voshage G, Zenz M. Histamine release and cardiovascular reactions to implantation of bone cement during total hip replacement. Anaesthesist. 1991:40(1):25-32.

4. Mitsuhata H, Saitoh J, Saitoh K, Fukuda H, Hirabayasi Y, Shimizu R, Hasegawa J, Matsumoto S, Enzan K. Methylmethacrylate bone cement does not release histamine in patients undergoing prosthetic replacement of the femoral head. Br J Anaesth. 1994;73(6):779-81.

5. Lamadé WR, Friedl W, Schmid B, Meeder PJ. Bone cement implantation syndrome. A prospective randomised trial for use of antihistamine blockade. Arch Orthop Trauma Surg. 1995;114(6):335-9.

6. Akin C. Mast cell activation syndromes presenting as anaphylaxis. Immuno Allergy Clin North Am. 2015;35(2):277-85. doi:10.1016/j.iac.2015.01.010.

7. Hailer NP, Garellick G, Kärrholm J. Uncemented and cemented primary total hip arthroplasty in the Swedish Hip Arthroplasty Register. Acta Orthop. 2010;81(1):34-41. doi:10.3109/17453671003685400.

8. Lazarinis S, Milbrink J, Mattsson P, Mallmin H, Hailer NP. Bone loss around a stable, partly threaded hydroxyapatite-coated cup: a prospective cohort study using RSA and DXA. Hip Int. 2014;24(2):155-66. doi:10.5301/hipint. 5000104. Epub 2014 Feb 3

9. New AM, Northmore-Ball MD, Tanner KE, Cheah SK. In vivo measurement of acetabular cement pressurization using a simple new design of cement pressurizer. J Arthroplasty. 1999;14(7):854-9.

10. Erpenbach J, Hofmeister E. Hypersensitivity to polymethylmethacrylate following shoulder hemiarthroplasty. Orthopedics. 2008;31(7):708.

11. Kaplan K, Della Valle CJ, Haines K, Zuckerman JD. Preoperative identification of a bone-cement allergy in a patient undergoing total knee arthroplasty. J Arthroplasty. 2002;17(6):788-91.

12. Krüger A, Hamann C, Brendel C, Ramaswamy A, Schnabel M, Neubauer A, Hofbauer LC. Multimodal therapy for vertebral involvement of systemic mastocytosis. Spine (Phila Pa 1976). 2009;34(17):E626-8. doi:10.1097/BRS. 0b013e3181a6bc4f.

13. Hofmann S, Hopf R, Huemer G, Kratochwill C, Koller-Strametz J, Schlag G, Salzer M. Modified surgical technique for reduction of bone marrow spilling in cement-free hip endoprosthesis. Orthopade. 1995;24(2):130-7.

14. Wang Y, Huang F, Chen L, Ke ZY, Deng ZL. Clinical measurement of intravertebral pressure during vertebroplasty and kyphoplasty. Pain Physician. 2013;16(4):E411-8.

15. Mizowaki T, Miyake S, Yoshimoto Y, Matsuura Y, Akiyama S. Allergy of calcium phosphate cement material following skull reconstruction: a case report. No Shinkei Geka. 2013:41(4):323-7.

16. Felton TW, McCormick BA, Finfer SR, Fisher MM. Life-threatening pulmonary hypertension and right ventricular failure complicating calcium and phosphate replacement in the intensive care unit. Anaesthesia. 2006;61(1):49-53.

\section{Submit your next manuscript to BioMed Central and we will help you at every step:}

- We accept pre-submission inquiries

- Our selector tool helps you to find the most relevant journal

- We provide round the clock customer support

- Convenient online submission

- Thorough peer review

- Inclusion in PubMed and all major indexing services

- Maximum visibility for your research

Submit your manuscript at www.biomedcentral.com/submit
) Biomed Central 